\title{
LOS LUGARES SAGRADOS EN LA REVUELTA DE LAS COMUNIDADES DE CASTILLA (1520-1521): EL ATAQUE A LAS IGLESIAS
}

\author{
POR \\ CLAUdio CÉSAR RIZZUTO ${ }^{1}$ \\ Universidad de Buenos Aires
}

\begin{abstract}
RESUMEN
El presente trabajo se ocupa de la destrucción, saqueo y deterioro de iglesias en el contexto de la Revuelta Comunera. En el marco de una concepción de la iglesia-edificio como lugar sagrado desarrollado durante la Edad Media, el sentido de dichos ataques adquiere particular importancia. Desde esta premisa, se analizan diferentes situaciones de violencia contra las iglesias, en especial el caso de la catedral de Santa María de Segovia. Luego de la casi destrucción de dicha catedral, se inició un proceso de reconstrucción del espacio sagrado de la ciudad. Por último, el artículo destaca la necesidad de considerar la actitud cambiante hacia las iglesias como lugar sagrado durante los sucesos de 1520-1521 en Castilla.
\end{abstract}

PALABRAS CLAVE: Revuelta Comunera; iglesias; lugares sagrados; reliquias.

\section{THE SACRED PLACES IN THE REVOLT OF THE COMUNIDADES OF CASTILE (1520-1521): THE ATTACK AGAINST CHURCHES}

\begin{abstract}
The present work deals with the destruction, pillage and deterioration of churches in the context of the Revolt of the Comuneros. Within the framework of a conception of the church-building as a sacred place developed during the Middle Ages, the meaning of such attacks becomes particularly important. From this premise, it analyses different situations of violence against the churches, especially the case of the Cathedral of Santa María de Segovia. After the almost destruction of this cathedral, a process of reconstruction of the sacred space took place in the city. Finally, the article highlights the need to consider the changing attitude towards the churches as a sacred place during the events of 1520-1521 in Castile.
\end{abstract}

KEY WORDS: Revolt of the Comuneros; churches; sacred places; relics.

Cómo CITAR ESTE ARTículo / CITATION: Rizzuto, Claudio César. 2019. «Los lugares sagrados en la Revuelta de las Comunidades de Castilla (1520-1521): el ataque a las iglesias». Hispania Sacra 71, 144: 427-437. https://doi.org/10.3989/hs.2019.030

\author{
Recibido/Received 02-02-2017 \\ Aceptado/Accepted 26-03-2019
}

\section{INTRODUCCIÓN}

El daño y la destrucción de iglesias han sido fenómenos recurrentes entre los movimientos sociales de la Edad Media y la Edad Moderna. Muchas veces, en un contexto de levantamiento o de conflicto social, se dañaban o destruían edificios eclesiásticos, en ocasiones en compañía de otros edificios. A primera vista, estas situaciones pueden

\footnotetext{
1 claudiorizzuto88@gmail.com / ORCID iD: https://orcid.org/0000-0003-4298-4207
}

considerarse como parte de un fervor popular, que al estilo de una ira arrasadora, destruía todo a su paso sin respetar nada. Sin embargo, la propia concepción de la iglesia-edificio como lugar sagrado para la cultura eclesiástica del Occidente medieval permite pensar estos episodios en un marco diferente. Así, resulta fundamental para analizar dichos ataques la interpretación que los propios eclesiásticos le otorgaban al lugar de culto, la cual pretendían extender como representación a nivel más amplio. Sobre las imágenes, Manuel Delgado Ruiz afirmaba que «el sentido de la destrucción de imágenes sólo se puede establecer conociendo a fondo lo 
que esas imágenes destruidas significaban para sus usuarios simbólicos». ${ }^{2}$ Este mismo aspecto debe tenerse en cuenta para estudiar la destrucción de edificios eclesiásticos.

Esta concepción de la iglesia-edificio como lugar sagrado, que se expondrá brevemente en el siguiente apartado, cobra importancia en el contexto de la Revuelta de las Comunidades de Castilla en 1520-1521 debido a la posición que ocupaban el ataque, deterioro y saqueo de iglesias en la enumeración de las faltas cometidas por los revoltosos. Como se verá, además de ser mencionadas recurrentemente como fenómeno de la revuelta, invitan a otra vía por la cual pensar las posibilidades y límites de la religiosidad propuesta por la jerarquía eclesiástica a comienzos del siglo XVI.

\section{LAS IGLESIAS Y LA IGLESIA EN LA EdAD MEDIA ${ }^{3}$}

La relación entre cristianismo y territorio ha tenido una larga evolución en Occidente. Destinos de peregrinaje como tumbas de santos o sitios de apariciones eran los lugares referidos comúnmente como sagrados. Sin embargo, ya desde la Antigüedad Tardía se incorporaron las iglesias como sacralizadas, abandonando cierto cristianismo inicial que caracterizaba a la Iglesia como la reunión de creyentes, sin necesidad de un lugar fijo, mucho menos considerándolo sagrado. El Derecho civil, a través del código teodosiano en el siglo $\mathrm{V}$, fue el primero en reconocer a las iglesias como lugares sacro-santos, calificando toda infracción hacia ellas como sacrilegio.

Posteriormente, la Eclesiología carolingia incorporó y desarrolló este aspecto, a la par de la vinculación entre Iglesia y sociedad, confundiendo, por ejemplo, expansión del Imperio con expansión de la Iglesia. La iglesia edificio, a partir de su consagración, se convertía en lugar sagrado de restauración sacramental. De este modo, desde la jerarquía eclesiástica, que en la figura del obispo consagraba los sitios, se desarrolló una verdadera Teología del lugar, una Eclesiología cuyo misterio radicaba en la dependencia entre un contenido (la Iglesia como comunidad de fieles y medio de salvación) y un contenedor (la iglesia edificio). Esta metonimia tuvo un rol fundamental en la Eclesiología occidental a partir del siglo IX. Se contradecía así la fórmula altomedieval "Ecclesia non in parietibus consistit», constituyendo "Une Église faite de "lieux" et de "murs"». ${ }^{4}$

A su vez, la aparición en los siglos posteriores de una historiografía dedicada a historiar las construcciones de las grandes iglesias, destacaba esta transformación de la puesta en valor del edificio eclesial por sí mismo. Se instaló la iglesia edificio como lugar de excepción en el paisaje social, afirmando la autoridad de la Iglesia como estructura de dominación, desde una perspectiva simbólica, debido a que hacía a Dios visible en la tierra. Canonistas y liturgistas subrayaban la necesidad de pasar por el edificio para acceder a la Iglesia.

\footnotetext{
2 Delgado Ruiz 2001: 29.

3 A lo largo del trabajo, se referirá a iglesia con minúscula como la iglesia-edificio y a la Iglesia con mayúscula en su sentido teológico más extendido, como comunidad de creyentes.

4 Lauwers 2005: 85. Esta obra, particularmente dedicada a los cementerios, cuenta sin embargo con un extenso tratamiento de la relación entre espacialización y espiritualización y la concepción de lugar sagrado en el cristianismo medieval, véase Ibídem: 23-88. También puede consultarse Zumthor 1994: 55-58.
}

Asimismo, la personificación de la iglesia edificio la convertía en una "santa de piedra», de modo que, en Occidente, «Dieu est devenu "de Pierre" $»{ }^{5}$ Como comenta Richard Kieckhefer: "Entering a church is a metaphor for entering into the presence of the holy». ${ }^{6}$ La eucaristía se confundía también con el lugar donde se realizaba: la iglesia edificio. Se debía 'estar' en la iglesia para 'ser' de la Iglesia, transitando por el edificio como medio para la salvación. De allí que se sugiriera que la iglesia era el 'primer' sacramento necesario para los otros sacramentos, el lugar donde realizarlos. ${ }^{7}$ En palabras de José Ángel García de Cortázar: «La conjunción de las áreas eucarística, martirial (o santoral) y bautismal convertía a la iglesia-templo en un polo de espacialización y de irradiación de lo sagrado». ${ }^{8}$ Por ello, "where there is an altar there is a church» y "The altar was considered too sacred». ${ }^{9}$ De esta manera, ante esta particular concepción de iglesia desarrollada durante la Edad Media, cobra un sentido específico el ataque o el no respeto a las mismas.

\section{LA Destrucción de Iglesias en la EdAd Media}

La destrucción de iglesias suele asociarse, tanto en la historiografía dedicada a la Edad Media como a la que se ocupa de los siglos posteriores, a los episodios iconoclastas. La destrucción de imágenes es una temática recurrente en la Historia del cristianismo, en especial para el cristianismo oriental y el cristianismo reformado. En la Europa occidental anterior a la Reforma del siglo XVI surgía como fenómeno herético, sobre todo en las herejías de los siglos XI a XIII. No obstante, pueden encontrarse episodios iconoclastas por fuera de situaciones de persecución o aparición de herejías. Estos sucesos, si bien refieren a la iconoclasia, aspecto que no se considerará aquí, permiten mostrar la complejidad de la religiosidad anterior a la Reforma por fuera de la Teología erudita. ${ }^{10}$

El problema de la destrucción y saqueo de iglesias se relaciona con la iconoclasia en al menos dos aspectos. Por una parte, fueron episodios que solían aparecer de la mano en la documentación: muchas veces quien destruía las imágenes también destruía la iglesia, en especial cuando no podía dividirse al santo de la iglesia que le pertenecía. Por ejemplo, era muy común que los ejércitos atacasen las iglesias de los santos protectores de sus enemigos, destruyendo tanto imágenes como edificios. La intención era dejar al enemigo sin su protección divina y de ese modo poder vencerlo. Así, la guerra se daba en un nivel sagrado y no solo en el campo de batalla. ${ }^{11}$ Por otra parte, ambas prácticas sirven

\footnotetext{
5 logna-Prat 2012: 443.

6 Kieckhefer 2004: 97.

7 Para todo este apartado la obra de Dominique logna-Prat es fundamental. Además de la antes citada pueden consultarse: logna-Prat 2016a y 2016b. Puede consultarse una síntesis también en Baschet 2009: 386-394.

8 García de Cortázar 2012: 298. Este autor ha abordado esta dimensión en numerosos trabajos tanto de su autoría como en colaboración, bajo el concepto de "organización socio-eclesiológica»: García de Cortázar 1999 y 2004; García de Cortázar y Teja Casuso 2016.

9 Kieckhefer 2004: 64 y 76.

10 Sobre la iconoclasia en la Edad Media occidental, puede consultarse el excelente artículo: Marchal 1995.

11 Se recogen muchos episodios en este sentido en la Guerra de los Cien años, al respecto, puede consultarse la monumental: Denifle 1897-1899.
} 
como aproximación a lo religioso en su dimensión material: la Reforma Protestante, en particular en sus versiones radicales, consideró el problema de las imágenes, entre otros aspectos, como la materialización de algo que debía permanecer inmaterial. En este contexto, proponer un lugar como consagrado podía generar tanto el rechazo como el culto a las imágenes. De este modo, si bien las posiciones reformadas respecto de lo material son diversas e imposibles de sintetizar aquí, sí puede retomarse este punto: ubicar la imagen alrededor de lo material abre paso a pensar el problema de una manera mucho más amplia, en relación con la concepción de lugar sagrado desarrollada por el cristianismo medieval. ${ }^{12}$

La destrucción de iglesias como fenómeno más o menos recurrente ponía en duda la relación establecida entre lugar de culto y salvación. Si se atacaba el lugar donde se realizaban las "oraciones más eficaces», otro medio de salvación debía ser posible. Estos "lapsus» en los que se suspendía la creencia en el lugar sumamente sacralizado, permiten colocar al límite la aceptación, sin miramientos, de la realidad eclesial-jerárquica. Como muchos historiadores han demostrado, la relación de los humanos con lo sagrado y la divinidad, resultaba diversa y no podía reducirse a cierto discurso eclesiástico, sumamente signado por la lucha contra los «enemigos» de la cristiandad.

Por otra parte, otros sucesos de la vida medieval pueden incluirse en esta complejidad de relaciones con cierta "propiedad" de los miembros de la Iglesia: los saqueos producidos contra las propiedades de obispos y papas durante la Edad Media y la primera Modernidad. Existen numerosos episodios en los que se mencionaba que al momento de la muerte o de la elección de un obispo o pontífice, sus propiedades podían ser saqueadas por la muchedumbre, en especial en el caso del obispo de Roma. Así, más allá de la dimensión ritual que pueda plantearse en esos hechos, interesa aquí destacar cierta familiaridad con el ataque a las que eran, en última instancia, propiedades identificadas con la jerarquía eclesiástica. Sin tratarse de "lugares sagrados», como puede ser el saqueo de un palacio pontificio o episcopal, permiten contextualizar la destrucción de iglesias entre otros atentados contra la propiedad eclesial, en algunos casos dedicadas al culto, en otras meras residencias de la clerecía. ${ }^{13}$ Inclusive, en palabras de Joëlle Rollo Koster, frente a los numerosos ataques contra las personas del clero: «The most widespread incidence of violence against the Church took the form of stealing and damaging the goods and property of the Church (spoliae bonorum ecclesiae) rather than its bodies». ${ }^{14}$

12 Sobre esta diversidad en la Reforma, véase Eire 1989.

13 Estos saqueos rituales a las propiedades de papas y obispos, son estudiados, de manera un tanto aproximativa, por Ginzburg 2004. Una visión crítica a la cuestión ritual de estos saqueos: Modigliani y Rehberg 2008. Joëlle Rollo-Koster ha dedicado numerosos trabajos a esta temática, uno reciente: Rollo-Koster 2014. Para diversas aproximaciones sobre la violencia y la Iglesia en la Edad Media, puede consultarse la obra colectiva: Kotecki y Maciejewski 2014.

14 Rollo-Koster 2014: 54. Por supuesto, el problema abordado aquí se vincula claramente con el problema de lo que podría denominarse anticlericalismo. Un panorama sobre el anticlericalismo en la Edad Media tardía y la primera Modernidad: Dykema y Oberman 1994. Sobre el problema del anticlericalismo en la Revuelta de las Comunidades de Castilla: Gutiérrez Nieto 1973: 358 y ss; Rizzuto 2015.

\section{El ataque a las iglesias en la Revuelta Comunera}

Previamente a la exposición de los registros documentales sobre el ataque a edificios eclesiásticos durante los sucesos de 1520-1521, cabe aclarar que estas agresiones presentaban en ocasiones el problema de la mediación del pillaje. Muchas veces, tanto en la Revuelta Comunera como en otros episodios de la Edad Media y la Edad Moderna, el ataque a las iglesias era intervenido por la cuestión del saqueo de sus riquezas, en algunos casos sin distinguir cuando se trataba de materiales vinculados al culto (cruces, estatuas, cálices, etcétera) de riquezas como dinero o joyas que solían guardarse en las iglesias para su protección.

No obstante, el pillaje, por asociarse a ciertas pasiones humanas más 'profundas' o 'salvajes' como la codicia o el 'impulso' de violencia, no debe excluir otras razones o contextos por los cuales estas conductas emergían. Inclusive, por ejemplo, en situaciones de iconoclasia enmarcadas en el proceso de reforma generado por el protestantismo, las autoridades promotoras del mismo debieron intervenir en la transformación del culto. Sin su participación, sectores populares lo realizaban provocando daños mucho mayores que incorporaban actos de pillaje y destrucción más extensivos que la mera quita de imágenes. ${ }^{15}$ Por ello, el saqueo de iglesias no debe ser descartado como mero exceso sin ninguna importancia religiosa: en el marco de una metonimia entre la Iglesia-comunidad de salvación y la iglesia-edificio planteada por la cultura clerical, todo ataque a los lugares sagrados puede ser analizado en pos de mostrar elementos de la complejidad de la religión medieval y moderna.

Los episodios de saqueos de iglesias para tomar los recursos que allí se encontraban aparecen en algunas ocasiones mezclados con sucesos en los que no está claro si el saqueo incluía también la toma de objetos destinados al culto. A su vez, el hecho de que otros testimonios aclararan también el ataque a elementos vinculados al culto dentro de las iglesias, permite colocar bajo la duda el resto de los testimonios, en relación con si se intervino o no en los objetos religiosos. Un ejemplo claro en ese sentido es lo reproducido por Alonso de Santa Cruz, donde una acusación fechada en febrero de 1521 por los gobernadores, en la que se narraban los delitos cometidos por los comuneros, mencionaba que actuaron: «saqueando los monasterios é iglesias y ornamentos de ellas». ${ }^{16}$

Manuel Danvila y Collado en su extensa obra sobre las Comunidades resume un documento donde se narraba lo acaecido en Valladolid en el invierno de 1521. Distintos referentes de los comuneros, entre ellos Antonio de Acuña y Juan de Padilla, intervinieron para hacerse con dinero de diversas instituciones o edificios eclesiásticos, muchas veces dejados allí por miedo de sus dueños a ser saqueados: «muchos depósitos en iglesias y Monasterios fueron tomados por fuerza y contra la voluntad de sus dueños». ${ }^{17}$

En la acusación del fiscal Pero Ruiz en el proceso contra el obispo Acuña, fechada el 16 de abril de 1524, se describían

15 Es a partir de este conflicto que se puede hablar de la formación de una teoría y una práctica legítima de la iconoclasia como respuesta, por parte de los dirigentes de las Iglesias reformadas, a los recrudecimientos de las profanaciones de los grupos populares. Sobre este problema: Christin 1991: 35 y ss.

16 Santa Cruz 1920, vol. 1: 395.

17 Danvila y Collado 1897-1900, vol V: 474. 
primero los crímenes cometidos por los revoltosos en general, entre ellos:

quemas de casas y fortalezas y robaron muchas Iglesias y monasterios y la plata y ornamentos dellos y hicieron muchas fuerzas y forzaron muchas mujeres honestas $y$ casadas, y forzaron y corrompieron muchas doncellas y mujeres vírgenes y quemaron Iglesias y monasterios. ${ }^{18}$

Posteriormente, el texto detallaba lo realizado por el obispo de Zamora en particular. Entre diferentes delitos y faltas puede destacarse que en la villa de Magaz

\begin{abstract}
hizieron muchas fuerzas a mujeres y robos y saqueo la dicha Iglesia y la plata della y robaron la cruz de plata de la dicha Iglesia y estando el dicho Obispo presente por su mandato partieron y hizieron pedazos la dicha cruz de plata con un hacha de hierro e azero y el la repartió entre los soldados. ${ }^{19}$
\end{abstract}

Luego, en la villa de Frómista, el obispo «consintio y ovo por bueno que empeñasen las cruzes y calices y toda la plata de la Iglesia y lo mismo hizo en la villa de Monzon y en otros lugares». ${ }^{20}$

En este contexto, más allá de ciertas puntualidades teológicas, pueden mencionarse la quizás exagerada visión de Pero Ximenez que en una carta a Carlos V en enero de 1521 relataba: "Como el Obispo de Çamora hubiese dominado y traido á su seta los lugares de Señorio de la tierra de Campos porque los realengos están en su herética opinion». ${ }^{21}$ Una relación del Almirante, que debía llegar a su majestad, también comentaba la situación en Tierra de Campos diciendo que los comuneros «roban iglesias martiriçan clérigos, hacen Herexias no pensadas».22 Si bien excede este estudio la cuestión de la herejía y el ataque a los miembros del clero, debe aclararse que estas calificaciones, para el caso del obispo Acuña en Tierra de Campos, no eran del todo azarosas ante el daño realizado en diferentes iglesias. ${ }^{23}$

Otorgando una connotación similar, la relación de Pedro de Alcocer, que se centra fundamentalmente en Toledo, comentaba que en esta ciudad «estando las Iglesias profanadas y cosas sagradas violadas y la Santa Iglesia con mil maneras de sacrilegio, y habiendo puesto algunos de ellos sus manos violentas en sus grandes tesoros». ${ }^{24}$ La referencia a una cuestión sacrílega era mencionada también por Juan Maldonado, una de las más interesantes narraciones de los comuneros. ${ }^{25}$ Al narrar el enojo con el obispo de Burgos, Juan Rodríguez de Fonseca, porque su hermano Antonio Fonseca era responsable del incendio de Medina del Campo, su casa y vicarios fueron atacados y «templis etiam, in quibus eius aliquam supellectilem compererant

18 Reproducido como apéndice en: Fernández Martín 1979: 498502, en este caso 498-499.

19 Ibídem: 501.

20 ídem.

21 Danvila y Collado 1897-1900, III: 76.

22 Ibídem. III: 247.

23 Se ha ocupado del problema de la herejía y el ataque al clero en la Revuelta Comunera, avanzando en el sentido que aquí se señala: Rizzuto 2015. Danvila y Collado hace mención a la existencia de una carta, que no reproduce, donde el licenciado Vargas comentaba al rey sobre el saqueo de iglesias y otros lugares en Tierra de Campos, cfr. Danvila y Collado 1897-1900, III: 201.

24 Alcocer 1872: 72.

25 Sobre este personaje: García y García 1983. occultari, minime parcunt [...] clerici feminaeque stupescunt atque sacrilegium detestantur $» .^{26}$

El proceso contra Juan Gaitán, caballero de la orden de Santiago que fue juzgado acabada la revuelta por su participación en la Comunidad de Toledo, es una fuente fundamental para reconstruir lo acaecido en esa ciudad. Entre numerosos crímenes, se lo acusaba: «tomasteis alguna plata de las iglesias y monasterios de esta dicha ciudad $» .{ }^{27}$ Varios testigos mencionaron que durante la revuelta se decía que Juan Gaitán y otros serían excomulgados por tomar dinero de las iglesias para sostener tanto la Comunidad local como la Santa Junta. ${ }^{28}$ Otro testigo, Juan Terrín de Guzmán, declaraba en favor del acusado afirmando que «nunca vio que el dicho Juan Gaitán se juntase con los alborotadores y comuneros a robar las iglesias ni monasterios ni casas particulares, ni tenía oficio de Comunidad $» .^{29}$ El escudero Martín Alonso, que también testificó de modo favorable a Gaitán, afirmaba que este sugirió que «no diesen consentimiento para sacar la plata de la Iglesia Mayor ni el pan del depósito». ${ }^{30}$ El mercader Gonzalo de Illescas declaraba en el mismo sentido agregando que Juan Gaitán había sostenido eso porque "no quería él estar descomulgado por ello». ${ }^{31}$ De este modo, si bien se excluía a Gaitán, no se desmentían los episodios.

Fray Antonio de Guevara en su epistolario, sumamente polémico en relación con la revuelta, afirmaba en una supuesta carta a Antonio de Acuña:

Bien sabéis vós, señor Obispo, que los soldados que allí morían eran descomulgados del Papa, traydores al rey, alborotadores del reyno, robadores de las yglesias, salteadores de los caminos de la república y mantenedores de la guerra. ${ }^{32}$

Se vinculaba nuevamente la figura del obispo Acuña con el robo a las iglesias y que serían descomulgados sus responsables. En otra carta, supuestamente a María de Padilla, contraponía a los «caballeros» que, a diferencia de los comuneros, «no roban yglesias». ${ }^{33}$ Asimismo, el citado edicto de los gobernadores de febrero de 1521, comentaba:

Y que habíais cometido y de cada día cometías otros muchos domicilios, robos, adulterios y estupros, forzando mujeres casadas y doncellas, sacándolas de las iglesias y de otros lugares sagrados, los cuales dichos delitos habían sido tantos y tan graves que con dificultad se podrían contar. ${ }^{34}$

Aquí si bien no se mencionaba un ataque a la iglesia edificio, sí se describían crímenes graves no respetando los lugares sagrados que protegían a las mujeres, haciendo alusión a los forzamientos antes expuestos.

26 Maldonado 1991: 204. Versión castellana: «ni siquiera perdonaron los templos en los que habían descubierto que se ocultaba alhajas [...] los clérigos y las mujeres asombrándose y aborreciendo el sacrilegio» (207 y 209).
27 Vaquero Serrano et al.
28 Ibídem: 200.
29 Ibídem: 302.
30 Ibídem: 167.
31 Ibídem: 154.
32 Guevara 2004: 265
33 Ibídem: 288.
34 Santa Cruz 1920, I: 396. 
La crónica anónima conservada en la British Library de Londres, publicada por José Manuel Nieto Soria, que narra aspectos de la historia castellana entre los reinados de Enrique IV y Carlos V, comentaba en las pocas páginas que dedica a la Revuelta Comunera:

En tanto resçio la locura e ynsolençia del pueblo, que las yglesias y templos de Dios no valían a las personas que en ellas se acogían, ni perdonavan a los bienes que los hombres en los templos ponían en guarda, mas todo lo robavan e tomaban sin porden alguna a su placer. $^{35}$

Otros casos que pueden mencionarse son los monasterios: si bien no se trata de lugares sagrados desde una perspectiva teológica, sí se trata de edificios eclesiásticos por lo que pueden analizarse en relación con el problema aquí tratado. Pedro Mártir de Anglería, por ejemplo, comentaba que los rebeldes "sacan por la fuerza las cosas depositadas en los conventos, hacia los cuales sienten un profundo desprecio». ${ }^{36}$ En un sentido similar, en el proceso contra Gaitán se señala que este acabó siendo acusado de traidor a la comunidad por diferentes sectores, sufriendo el saqueo de su casa y se creía que estaba refugiado en el monasterio de la Trinidad por lo que amenazaron que entrarían a matar a Gaitán y «le derribaran el monasterio». ${ }^{37}$

Antes de avanzar al caso de la catedral de Segovia, que se analizará particularmente por la riqueza de la documentación al respecto, debe aclararse la acción de ciertos anti comuneros frente a una iglesia de Mora que se encontraba encastillada. Siguiendo el relato de Santa Cruz:

Los soldados comenzaron a combatir á los que estaban dentro de la iglesia de Mora, y estando los unos combatiendo y los otros defendiéndose permitió Dios que se prendiese fuego en el baluarte y de él que se prendiese la iglesia, y que de 3.000 ánimas que estaban dentro de ella todas se quemasen sin escapar una viva. ${ }^{38}$

El comentario que realizaba el cronista, más allá de la duda ante la cifra de muertos, genera cierto impacto a la hora de considerar las faltas, crímenes o excesos provocados por los realistas:

Esto que aconteció en Mora fué uno de los más terribles y desastrados casos que acontecieron en nuestros tiempos, porque los desdichados ni eran moros ni judíos para que los quemasen vivos, y si acaso eran culpados los padres eran inocentes sus hijos, y aunque fuese grande la desobediencia que tuvieren al Rey los de Mora fué muy excesiva la crueldad que se hizo en aquella iglesia. ${ }^{39}$

El interés del comentario excede los objetivos de este estudio, pero resulta útil para considerar que el problema de las disidencias casi cotidianas, como la suspensión del respeto a los lugares sagrados, no era exclusivo de los comuneros, sino que era un problema extendido de la sociedad castellana del siglo XVI.

\footnotetext{
35 Nieto Soria 2015: 178.

36 Anglería 1955, XII: 131.

37 Vaquero Serrano et al. 2001: 346.

38 Santa Cruz 1920, I: 475.

39 Ídem.
}

\section{LA DESTRuCción de LA CATEDRAL DE SEgovia}

Segovia fue uno de los centros de poder comunero más importantes y donde los episodios fueron más violentos. Suele mencionarse en este punto el asesinato de Rodrigo de Tordesillas, procurador que había votado el servicio en las Cortes de Santiago-La Coruña, el cual tuvo aparentemente tintes de violencia ritual. ${ }^{40} \mathrm{Si}$ bien existen estudios detallados sobre la Revuelta Comunera en Segovia, la destrucción de la catedral durante la misma no excede la mera mención. ${ }^{41}$ Se debe recurrir a trabajos dedicados a la construcción de la catedral que la reemplazó, y que se conserva en la actualidad, para enterarse de un modo más detallado de esos sucesos. ${ }^{42}$ No obstante, el caso de la catedral de Santa María se puede proponer, igual que el incendio de Medina del Campo durante la revuelta, como máximo ejemplo de la huella material duradera de los hechos de 1520-1521 en Castilla. ${ }^{43}$

El relato del racionero Juan de Pantigoso, en un memorial escrito por orden del cabildo y dedicado a su obispo poco después de la derrota de los comuneros, es el testimonio más detallado de estos sucesos. ${ }^{44}$ Luego de realizar una breve historia de Segovia y su catedral, describe los hechos alrededor de dicha iglesia. La antigua catedral estaba ubicada frente al alcázar, por lo que con su torre funcionaba como contrapunto del mismo y muchas veces era vista como una amenaza militar, como ya lo mostraba la intención de Enrique IV por trasladarla. ${ }^{45}$ Los canónigos pretendían además su traslado desde mediados del siglo XV, de modo de acercarla al nuevo centro urbano. ${ }^{46}$ Asimismo, desde la década de 1460 albergaba las reliquias de san Frutos y sus hermanos san Valentín y santa Engracia. ${ }^{47}$

Luego del asesinato de Rodrigo de Tordesillas en mayo de 1520, los partidarios del rey se refugiaron en el alcázar y en la catedral. Los canónigos de dicha catedral, ante el peligro, se retiraron primero a la iglesia de San Andrés y después al convento de Santa Clara.

En el contexto del conflicto por el control de la ciudad, los rebeldes pusieron cerco a la catedral, que se encontraba entre ellos y el alcázar. Francisco de Villareal, tesorero de la Casa de la Moneda y testigo recogido por Pantigoso, mencionaba que una vez cercada la catedral «comenzaron á picar la pared de la capilla mayor para derrocar como después la derrocaron $»{ }^{48}$ Frente a esta situación los miembros del cabildo

40 Sobre la muerte del procurador de Segovia y la violencia: Haliczer 1976; MacKay y McKendrick 1988.

41 Álvarez de Frutos 1987. El libro de Pablo Sánchez León, si bien tiene conclusiones globales para el estudio de la revuelta, analiza puntualmente los casos de Guadalajara y Segovia, sobre el caso segoviano: Sánchez León 1998: 212-223. Sobre las Comunidades en Segovia también puede consultarse: De La Peña Barroso 2015; Álvarez de Frutos 1984; Fernández Martín 1981; Lecea y García 1906.

42 Por ejemplo: Cortón de las Heras 1997: 38-53; Soto Cano 2005; López Díez 2006.

43 Menciona este punto Álvarez de Frutos 1987: 9. Ha realizado una aproximación a la destrucción del patrimonio durante la revuelta Vasallo Toranzo 2017.

44 Lecea y García 1899.

45 Cortón de las Heras 1997: 17 y ss.

46 Soto Cano 2005. Sobre la ciudad de Segovía hasta las puertas de las Comunidades, la obra clásica: Asenjo González 1986.

47 Sobre el hallazgo de las reliquias: Contreras Jiménez 1989.

48 Lecea y García 1899: 243. 
visto que los cercados picaban la pared de la capilla mayor y querían ponerle fuego para la derrocar, temiendo que con ella cayese la capilla de Sant Frutos por estar circunligada con la mayor, y porque las reliquias de los dichos cuerpos santos no se maltratasen ó perdiesen, las habían quitado del lugar donde estaban y llevado á la capilla que está dentro de los alcázares. ${ }^{49}$

Cabe recordar, que además del miedo al daño por derrumbe que describe el memorial, las reliquias fueron objeto de robo durante toda la Edad Media, por lo que tampoco era deseable que las mismas cayeran en manos equivocadas, fuera del control del clero catedralicio. ${ }^{50}$ Asimismo, si bien las reliquias resultaron intactas, como se verá, existió, según los hechos que recoge el memorial, cierta violación a la sacralidad de las mismas que debió ser reconstruida posteriormente.

Continuando el relato, en palabras de Diego de Colmenares, historiador de la ciudad de Segovia del siglo XVII y quien conservó el memorial citado:

Trataron de picar y romper la capilla mayor de la Catedral para señorearse de la iglesia y torre; y de allí combatir el alcázar con mayor ímpetu y ventaja. El cabildo salió en defensa a decirles cuan injusto era derribar un templo, y tan suntuoso, y más para hacer guerra a quien sirviendo a su rey, defendía su alcázar. La confusión era tanta y la canalla tan ignorante y furiosa, que entre otros disparates respondían, que la iglesia era de la ciudad..$^{51}$

Posteriormente, realizado el agujero en la catedral, «Peleose dentro con más odio al enemigo que veneración al templo». ${ }^{52}$ Resultado de estos enfrentamientos, Pantigoso retrataba un panorama desolador, finalizada la lucha:

los dichos Deán y Cabildo se quisieron tornar, y tornaran á la dicha Iglesia, sino estuviera, como estaba y aun está, derribada y aportillada, y por muchas partes destechada y desolada, disipada y destroida; los altares derrocados y profanados; los Crucifijos é imágenes de nuestra Señora y de otros santos descabezadas, los brazos y piernas hechas pedazos; los órganos grandes y los otros dos pares, que estaban sobre el coro, quebrados y agugereados de escopetadas y otros tiros; las sillas del coro trastornadas y evertidas de sus lugares, y muchas dellas quemadas, y otras puestas por defensa y albarradas; hecho dentro y alrededor cavas, fosados, minas y contraminas; y por quitar las losas y laudes de la Iglesia para hacer barreras y defensas, los huesos de los finados sacados y desenterrados; y hechas otras cosas semejantes. ${ }^{53}$

\section{Lecea y García 1899: 225.}

50 Sobre este problema, la clásica obra: Geary 1990.

51 Colmenares 1969-1974, II: 196-197 [Primera edición de 1637]. En esta narración, Colmenares parece estar siguiendo casi literalmente dos fuentes. Por un parte, el citado Pantigoso quien afirmaba que ante la advertencia de los canónigos los comuneros respondieron «diciendo que la iglesia era de la ciudad, para el reedificarla y hacerla no se tenga por agena» Lecea y García 1899: 232. Por otra parte, el descargo de Juan Rodríguez, miembro del cabildo, quien aseguraba algunos años después, haber amonestado a los revoltosos para «que considerasen cuán injusto era derribar un templo y tan suntuoso, y más para hacer la guerra a quien sirviendo a su rey, defendía su Alcázar», citado en Cortón de las Heras 1997: 41.

52 Colmenares 1969-1974, II: 197

53 Lecea y García 1899: 226.
Leído rápidamente, el fragmento recoge elementos de iconoclasia. No obstante, según se ha reconstruido hasta aquí, no habría sido un ataque directo a las estatuas de santos y de la virgen, sino más bien de un «daño colateral» producto de la batalla en el interior de la catedral. ${ }^{54}$ De una u otra manera, se trataba de una falta a la noción de iglesia edificio como lugar sagrado. En este caso, no solo se destruyeron aspectos materiales en general, sino también objetos de culto como crucifijos y estatuas. Por ello, como se desprendería de la declaración de Colmenares antes citada, habría existido un olvido o suspensión del respeto que debían recibir los lugares de culto. Cabe aclarar que esta situación de combates en las iglesias era recurrente tanto en los duelos nobiliarios como en enfrentamientos entre plebeyos, que muchas veces contra la opinión de los miembros del clero se realizaban en parroquias y hasta en cementerios. ${ }^{55}$ Así, la situación particular de la revuelta de los Comuneros, y el hecho de tratarse de la catedral de Segovia, permiten conocer con mayor precisión episodios que suelen repetirse muchas veces en la documentación sin demasiada aclaración.

Este punto también puede percibirse a la hora de dilucidar quienes destruyeron la catedral. Si se sigue a Diego de Colmenares, como ya se ha citado, los responsables de los destrozos fueron una "canalla tan ignorante y furiosa». ${ }^{56}$ No obstante, como ha señalado el editor del memorial de Pantigoso, la situación en Segovia fue diferente: la acusación de Colmenares probablemente se debió a que trataba de "salvar» el honor de los sectores privilegiados de la ciudad. ${ }^{57}$ Juan de Pantigoso realizaba una evaluación completamente distinta:

Y sin falta se puede decir por ella lo que el profeta Jeremías por Jerusalén en sus lamentaciones; y con tanta más razón cuanta más diferencia hay agora á lo de entonces; porque si el templo de Jerusalén entonces se destruyó, fué por los enemigos y gentes de extraña nación y fe, y agora el de Segovia por los amigos y de una misma fe y nación. Proh dolor! y cosa digna de lamentar que los propios naturales, así los de fuera que la tenían cercada como los cercados de dentro, olvidando á Dios y á su Madre gloriosa, derrocasen y destruyesen, como derrocaron y destruyeron, su propia madre é Iglesia mayor, siendo como fueron amonestados y requeridos por parte del Cabildo y personas de él que no la derrocasen ni maltratasen. ${ }^{58}$

El texto aludía a Jeremías 39: 1-4, donde se narra la efectiva, luego de haber sido profetizada en Jeremías 21:

54 Cortón de las Heras menciona una posible exageración de Juan de Pantigoso en este punto, pero en referencia al estado de la construcción en general de la catedral, no así en relación con el tratamiento hacia los objetos de culto, ver Cortón de las Heras 1997: 42, n. 50.

55 Stuart Carroll, por ejemplo, recoge alrededor de cincuenta casos de duelos o emboscadas en cementerios e iglesias francesas entre 1470 y 1660. Véase Carroll 2006: 121-124. Robert Muchembled, por su parte, asocia la violencia en estos lugares, al igual que en las plazas y tabernas, con hacerla perfectamente visible y memorable, de modo que a la vez que sería "una falta de respeto» contra el lugar, no dejaba de exaltar su centralidad en la comunidad. Véase Muchembled 2010: 84-85.

56 Colmenares 1969-1974, II: 197. La participación fue uno de los elementos clave y a la vez de variada interpretación en relación con de la Revuelta Comunera: Maravall 1979: 176-185; Pérez 1999: 451-455; Martínez Gil 2002; Oliva Herrer 2018.

57 Lecea y García 1899: 257 ss.

58 Lecea y García 1899: 227. 
1-14, invasión de Nabucodonosor, rey de Babilonia, sobre Jerusalén. Pantigoso comparaba como, mientras en un caso el templo de Jerusalén fue destruido por invasores extranjeros, en el otro la catedral de Segovia fue destruida por personas de la misma fe y nación. Todos los sectores fueron partícipes y "olvidaron" a Dios para cometer los actos que cometieron. Dicho olvido, consistiría en dejar de lado la condición sagrada del sitio. Para considerar la magnitud de la situación, en este memorial se comparaba la destrucción de la catedral con la de la misma Jerusalén a su vez que se recurría a la clásica metáfora de la Iglesia como madre. ${ }^{59}$ Por último, se mencionaba que se ignoró la advertencia del cabildo de detener la contienda en ese sitio sagrado.

Los sucesos pudieron haber merecido una demonización de los actores, como se encuentra en otras referencias durante la Revuelta Comunera, no obstante, el argumento que realiza el autor resulta más interesante para los intereses de este trabajo. ${ }^{60}$ Sin dejar de pertenecer a la misma fe y nación que Pantigoso, tanto comuneros como realistas suspendieron dicha creencia, actuando del modo que actuaron. Este "olvido» o suspensión abriría un espacio para pensar los modos de actuar de la creencia en la Castilla del siglo XVI. Sin expulsar a los segovianos del cristianismo, sí puede sugerirse cierta heterogeneidad en sus modos de practicarlo: la metonimia Iglesia comunidad de salvacióniglesia edificio no operaba de manera rígida y continua en los sujetos de la época. ${ }^{61}$

\section{LAS RELIQUIAS DE SAN FRUTOS Y LA RE-SACRALIZACIÓN DE LA IGLESIA SEGOVIANA}

Puede considerarse como señal del daño causado por los sucesos que se han relatado la necesidad posterior de re-sacralizar la Iglesia segoviana. Se trata de un proceso en cierta medida comparable con situaciones de ataque a las iglesias y sus objetos sagrados mucho más extremos como el caso de la iconoclasia hugonote en la Francia en la segunda mitad del siglo XVI. En respuesta a los ataques sufridos, se inició en la Iglesia Católica francesa un proceso de re-sacralización de los lugares e imágenes que habían sido objeto de la intervención hugonote. Esto no solo restauró la posición de los clérigos en la sociedad, sino que también implicó una verdadera revancha litúrgica y estética contra los protestantes derrotados. Como se verá en el caso segoviano, una manera fundamental de recuperar el prestigio perdido era que las imágenes que habían sido atacadas se convirtieran en medio para la realización de milagros. ${ }^{62}$ En palabras de Olivier Christin para la Francia posterior a las Guerras de Religión, se trataba de «la reconstruction de la frontière entre sacré et profane, temporairement transgressée par le sacrilège». ${ }^{63}$

\footnotetext{
59 Sobre la metáfora «Mater Ecclesia» logna-Prat 2012: 318-323.

60 Sobre lo diabólico en la revuelta de las Comunidades de Castilla: Rizzuto 2014.

61 Sobre las diversas resistencias al discurso eclesiástico de la metonimia entre Iglesia e iglesia-edificio en la Edad Media: logna-Prat 2012: 487-605.

62 Sobre este proceso: Christin 1991: 177 y ss.

63 Ibídem: 239.
}

El caso segoviano no refiere a imágenes sino a reliquias, particularmente, las reliquias de san Frutos y sus hermanos san Valentín y santa Engracia. Desde el momento de su aparición en Segovia hacia 1460, siguiendo el tópico de las inventiones de reliquias, produjeron numerosos milagros. Como afirma el memorial que se viene citando: "los cuerpos y santas reliquias del señor San Frutos, San Valentín y Santa Engracia sus benditos hermanos, fueron hallados, por cuyos méritos Dios nuestro Señor hizo muchos milagros». ${ }^{64}$

El cabildo recibió licencia del obispo el 24 de octubre de 1522 para trasladar las reliquias del alcázar, donde se encontraban resguardadas desde los incidentes, hasta la iglesia de Santa Clara, lugar provisorio donde actuaba el cabildo. ${ }^{65}$ El traslado se realizó mediante una numerosa procesión con participación tanto de religiosos como de laicos. Al momento que un pequeño grupo de clérigos abrieron el arca de las reliquias "parecieron ciertos huesos de cuerpos humanos, de donde salió muy gran fragancia de suavísimo olor en presencia de todos los que allí estaban $"{ }^{66}$ retomando un aspecto fundamental de la santidad cristiana: la relación entre el contacto divino y determinado aroma. ${ }^{67}$ Poco a poco, si se sigue el relato del memorial, se observa cómo se construía esta restauración del orden sagrado previamente atacado durante la revuelta. En relación con el traslado de las reliquias Pantigoso comentaba a su obispo:

Que vuestro Cabildo, muy magnífico Señor, acordándose de las cosas pasadas, con temor que en esta translación no hubiese algún escándalo ó disensión estuvo movido de no llamar las Religiones para esta procesión, si no fuera porque vuestra Señoría les escribió y embió á mandar. Así que, el concierto dicho, que en esta procesión ovo, parece milagrosamente hecho. No solo en esto pero en todo lo demás no ovo escándalo, desmán ni desconcierto el menor del mundo de los que suelen acaecer donde concurren mucha gente como en esta concurrió; que sin falta fué una procesión tan concertada y tan devota, cual nunca en esta ciudad fue vista. ${ }^{68}$

El miedo al desorden de los canónigos no solo respondía a razones políticas inmediatas sino también al ordenamiento cósmico. Como diría Michel Pastoureau, para esta sociedad las cosas debían quedarse en su lugar, para respetar el orden deseado por Dios, siendo cualquier transgresión de dicho orden posible de calificarse como un ataque contra la Divinidad misma. ${ }^{69}$ Puede verse aquí como bajo la sospecha de un milagro según la fuente, el orden y la concordia fue devuelta a la ciudad. Asimismo, la propia situación de traslado de las reliquias pareciera suspender cierto carácter inherentemente desconcertante del mundo. Como existía un orden divino que debía recuperarse, a la vez se encontraba la conciencia de la imperfección de la vida en este mundo. ${ }^{70}$

\footnotetext{
64 Lecea y García 1899: 216-217.

65 Ibídem: 236-237.

66 Ibídem: 245.

67 Sobre la santidad en la Edad Media: Brown 1981; Kleinberg 2005; Vauchez 2014. Sobre el olor a Santidad: Albert 1990. Sobre este aspecto en la Edad Media hispánica: Guiance 2009.

68 Lecea y García 1899: 249.

69 Cfr. Pastoureau 2006: 20.

70 Un ejemplo claro de esta tensión puede encontrarse en la misma Iglesia, a través de ideas como "Iglesia peregrina» o "Ecclesia Semper Reformata». Si bien se trata de un problema clásico de las reflexiones eclesiológicas no puede abordarse aquí más que como ejemplo del
} 
Una vez trasladadas las reliquias, comenzó el proceso de realización de milagros, también como reflejo del cumplimiento de la voluntad divina y restauración de lo sagrado en la ciudad. Comenta el memorial:

No es cosa de callar, ilustrísimo Señor, lo que por esta translación de aquestos cuerpos santos y por sus méritos Nuestro Señor maravillosamente paresció obrar en esta ciudad; mas es justo y digno de decirse y con letras inmortales escrivirse; pues á todos los de ella es notorio que, antes de este dia, hartos días que cada semana fallescían en esta ciudad y arrabales veinticinco ó treinta personas de pestilencia y modorrilla; y desde el dia que las santas reliquias se trasladaron, luego la pestilencia milagrosamente cesó, y los que después han fallecido ha sido de otras enfermedades y no de pestilencia, como ante mí lo han testificado los médicos de esta ciudad. ${ }^{71}$

Puede percibirse aquí como el milagro acabó con enfermedades que se habían extendido en la ciudad, típicas en los tiempos posteriores a una situación de guerra o conflicto. Asimismo, se encuentra cierta dimensión de construcción del milagro por parte del autor, ya que no pareciera ser algo conocido popularmente, sino que él tuvo que confirmar que la peste había cesado consultando con los médicos, en un contexto en que algunas muertes continuaron produciéndose.

El segundo milagro se refiere a un tintorero y a su esposa que no podían concebir:

En la dicha procesión vinieron entre la otra gente uno que se dice Pero López tintorero y Francisca de Dueñas su muger, vecinos de esta ciudad [...] esta muger de bien estaba avida y reputada por estérile y mañera: y así, el marido y la muger con muchas lágrimas y devoción se encomendaron á San Frutos fuese intercesor á Nuestro Señor les diese fruto de bendición con que él fuese servido y á quien pudiera dejar sus bienes y hacienda. Y así, aquella mesma noche siguiente la susodicha se empreñó de un hijo que parió... dias del mes de..., que fue dentro ó casi á los nueve meses; y por reverencia de San Frutos pusieron al niño por nombre Frutos, como el padre y la madre ante mí testificaron. ${ }^{72}$

Si bien puede parecer un milagro menos importante que detener la peste, no deja de ser significativo en tanto permite consolidar la función matrimonial desde la perspectiva de la Iglesia siguiendo el mandato bíblico. A su vez, volvía a aparecer la cuestión de la testificación, de modo de ordenar y presentar pruebas de la intervención divina en el caso. ${ }^{73}$

problema mencionado. La idea de una Iglesia en destierro y a la vez ya reino de Dios se remonta cuanto menos a Agustín de Hipona, cfr. Congar 1976: 6-7. Como síntesis eclesiológicas en este punto pueden consultarse: Küng 1968: 381-440; Pié-Ninot 2006: 599-604. La cuestión se complejiza si se considera la equivalencia entre Iglesia y Sociedad para la Edad Media propuesta fundamentalmente por Alain Guerrau y que recientemente ha sido llevada a diferentes caminos con el importante libro de Dominique logna-Prat sobre el peso del discurso eclesiológico en la formación de la Sociología moderna. Cfr. Guerreau 2002: 23-25, entre otros trabajos, y logna-Prat 2016. Cabe aclarar, que este autor señala que para los siglos XIV y XV cierto «realismo eclesiológico» propio de esos siglos perjudicó la posibilidad de confundir Iglesia con sociedad de un modo palpable como se venía realizando, de modo de abrir un espacio para el surgimiento de un pensamiento político autónomo, cfr. ibídem: 163-172.

71 Lecea y García 1899: 250.

72 Ídem.

73 Sobre los milagros en la Edad Media: Ward 1987; Sigal 1985.
En pos de esta re-sacralización no solo poseían un rol estos milagros contemporáneos a los hechos, sino que se destacaban los pasados, recargando el poder que poseían las reliquias y las ventajas de conservarlas como correspondía. Relata el memorial que en la misa que se realizó por la traslación de las reliquias se hizo:

Un devoto y breve sermón, bien aplicado al acto y translación de dichos cuerpos santos, tocando brevemente algunos de los milagros que en esta ciudad Nuestro Señor había hecho por sus méritos é intercesión [...]los cuales milagros, todos los que allí se hallaron y los oyeron, mostraron mucha consolación y dieron loores á Nuestro Señor. ${ }^{74}$

De esta manera, el proceso de re-sacralización estaba completado luego de graves episodios contra la Iglesia de Segovia. El último aspecto que puede mencionarse es la participación que tuvo la población, aparentemente en todos sus estamentos, en financiar la reconstrucción de la catedral luego que el Ayuntamiento de Segovia se reconociera responsable de la destrucción de la misma. ${ }^{75}$ Puede percibirse aquí cierta intención de redención o búsqueda de perdón ante la falta cometida ya que, en palabras de Cortón de las Heras: «con tal entusiasmo y fervor que el llevar a cabo las ofrendas, en dinero o en especies, el acarrear materiales o el echar piedra de la antigua catedral constituía un auténtico festejo ${ }^{76}{ }^{76}$ Así, el compromiso de los segovianos tomaría cierto tinte de compensación o redención: los «mismos» que la destruyeron luego se ocuparon de su reconstrucción.

\section{REFLEXIONES FINALES}

¿Qué cambió entre la Revuelta Comunera y los años posteriores como para provocar estas reacciones opuestas? La etiqueta alrededor de lo que puede llamarse resacralización, con la procesión y los milagros confirmaría que efectivamente la catedral de Segovia sufrió una ofensa grave en términos también religiosos, de allí la necesidad de restablecer la sacralidad de los espacios eclesiásticos de la ciudad. El relato que se ha recogido permite resaltar la distinción entre los daños producidos a edificios y propiedades de lo sucedido con la Iglesia segoviana: toda la ceremonia y reconstrucción simbólica posterior muestra su excepcionalidad.

De esta manera, tanto la destrucción de las iglesias como su posterior re-sacralización, como en el caso segoviano, permiten mostrar las dudas que existían alrededor de la creencia extendida y permanente en esta noción de iglesia-edificio como lugar sagrado y de realización sacramental. Esta cuestión cobra mayor importancia por encontrarnos fuera del contexto de las confesiones reformadas que surgieron en el siglo XVI, algunas de las cuales sostenían

74 Lecea y García 1899: 251.

75 Cortón de las Heras 1997: 51. En este punto, si se sigue a Asenjo González, deben destacarse las relaciones relativamente pacíficas entre el cabildo y el concejo de la ciudad a lo largo del período anterior a la revuelta: Asenjo González 1986: 553-554.

76 Ibídem: 61. Sobre la financiación de la construcción de la catedral, desde una perspectiva contable, puede consultarse el reciente estudio: Cillanueva de Santos 2009. 
el rechazo a la posibilidad de materializar lo sagrado como una dimensión fundamental y explícita. ${ }^{77}$

En el período anterior a la Reforma, la recurrente "falta de respeto» a la metonimia Iglesia e iglesia-edificio, fundamental en la construcción del poder temporal y espacial de la corporación eclesiástica, colocan límites a la posibilidad de considerarla una creencia estable. Si bien se trata de un problema de extrema complejidad, difícil de resolver en pocas líneas, sí quisiera sugerir que no debe apuntarse a una mera disidencia respecto de la cultura eclesiástica oficial, al menos no si se entienden lo oficial y su disidencia como dos polos separados y estancos. La posibilidad de buscar una cultura popular, en este caso sumamente "materialista», que, quizás por su sencillez, rechazaría los preceptos eclesiásticos más «idealistas» no ha dejado de mostrar muchas dificultades. ${ }^{78}$ No obstante, más allá de estos problemas de conceptualización, ya desde la década de 1970, cuanto menos, la historiografía ha destacado la diversidad de la religiosidad en la Edad Media y la primera Modernidad. El mundo religioso medieval se ha vuelto cada vez más complejo, no solo mostrando disidencias sino también mutuas dependencias. Propuestas como la contraposición contundente entre cultura de elite y cultura popular, muy importantes para disparar investigaciones, se han desplazado por, en palabras de Christine Caldwell Ames,

A rich ramification, then, of this expanded view of "the religious» is to bypass the binaries of «lay/clerical» and "popular/elite», in favour of evoking the roominess of orthodoxy, the amount of shared territory, and the co-existence of multiple Christianities. ${ }^{79}$

En este contexto, la importante reunión de prácticas y declaraciones que mostrarían esta complejidad, dejando de lado el problema de la hostilidad de las fuentes en muchos casos, no puede explicarse solamente por la existencia de cierto núcleo cultural irreductible y separado que era ajeno a la cultura eclesiástica. Las creencias de las personas resultaban discontinuas, contradictorias e inclusive anacrónicas respecto de si mismas. ${ }^{80}$ La definición de Gavin Langmuir de religiosidad, en contraposición a su definición de religión, como «fluid» y "constantly changing» puede ser útil en este sentido. ${ }^{81}$ Así, lejos de poder hallar cierto «espíritu» o «espíritus» de época que expliquen todos los comportamientos, debe plantearse cierta heterogeneidad en la religiosidad

\footnotetext{
77 Para este problema es importante el trabajo: Eire 1989.

78 Un panorama sobre este problema puede encontrarse en Benigno 2013: 107-145.

79 Ames 2012: 337. Sobre este problema de la religión medieval y su complejidad, también puede consultarse Van Engen 1986, 2008; Ames 2014.

80 Esto puede desprenderse de la crítica a la idea de espíritu de época, que en las palabras de Siegfried Kracauer, se basa en la creencia de que la gente realmente «pertenece» a su período, cfr. Kracauer 2010 109. A su vez, no se puede evitar remitir a las reflexiones de Jacques Derrida respecto de la fórmula "The time is out of joint» refiriéndose a una noción de tiempo como desencajado, desajustado, inarmónico, dislocado, desacordado, etcétera. Cfr. Derrida 1995: 17-36.

81 Cfr. Langmuir 1990: 161. No obstante, la propuesta de Langmuir sobre la religiosidad se relacionaba fuertemente con una dimensión individual, son los individuos los que otorgan pluralidad y fluidez. Aquí, en cambio, no se ha llegado a un nivel de análisis individual, tratándose en principio de una dimensión más general o «estructural». Cfr. Ibídem: 158-176.
}

tardomedieval, que implique que elementos a priori fundamentales por momentos dejasen de serlo, y los mismos grupos o personas por momentos actuaran como si creyeran y por momentos como si no creyeran determinadas posiciones. ${ }^{82}$ Se debe continuar avanzando en esta dimensión ambigua y escindida de la cultura de aquellos siglos, de la que la destrucción de iglesias no puede ser más que una manera de aproximarse al problema. De otro modo, se cae en posiciones que consideran estas experiencias como un exceso que a la vez las expulsa del estudio histórico.

Asimismo, si se trata de excesos, desbordes o suspensiones, ¿qué sucede cuando se las coloca en el centro de la escena? ¿Qué experiencia religiosa resulta del ataque a los espacios sagrados en lugar de respetarlos? ¿Qué religión permite volver de esta profanación ${ }^{83}$ A pesar de no poder resolver estos interrogantes en este contexto, el recorrido realizado destaca su pertinencia.

El análisis de una situación de guerra como la Revuelta de las Comunidades de Castilla habilita a encontrar escenarios extremos donde suelen aparecer elementos difíciles de hallar de otro modo. Sin embargo, no se trata de una manifestación «verdadera» frente a situaciones de «contención» o "disimulo» cuando no hay conflicto. El ámbito de las Comunidades generaría que ciertas posiciones se extremen y aparezcan a primera vista como inusuales, pero que al surgir en cada situación de conflicto no podrían remitirse a una excepcionalidad. A su vez, en muchos casos se trata de elementos que pueden hallarse, quizás de un modo menos explícito, en épocas de estabilidad. Si bien resulta difícil ser contundente en este punto, puede afirmarse que el estudio de una revuelta atendiendo a su dimensión religiosa puede tener consecuencias historiográficas no solo para el estudio de dicha revuelta en sí misma, sino para el estudio del fenómeno religioso en general. ${ }^{84}$ Frente al estudio de la relaciones de los humanos con sus lugares sagrados en la Europa medieval y moderna, su destrucción es un aspecto que no suele aparecer de modo generalizado en las aproximaciones historiográficas, aunque se trate de una dimensión sumamente presente según se ha tratado de mostrar aquí.

\section{FUENTE}

Alcocer, Pedro de. 1872. Relación de algunas cosas que pasaron en estos reinos desde que murió la reina Católica doña Isabel, hasta que se acabaron las Comunidades en la ciudad de Toledo, ed. Antonio Martín Gamero. Sevilla: Sociedad de Bibliófilos Andaluces.

Anglería, Pedro Mártir de. 1955. «Epistolario». En Documentos inéditos para la Historia de España, edición de José López de Toro. Madrid: Imprenta Góngora, 4 vols.

Colmenares, Diego de. 1969-1974 [Primera edición de 1637]. Historia de la insigne ciudad de Segovia y Compendio de las Historias de Castilla. Segovia: Academia de Historia y Arte de San Quirce, 3 vols.

82 El panorama se complejiza aún más si se considera la dimensión práctica de la noción de creencia: Certeau 1981.

83 Recuérdese que el obispo de Segovia otorgó un perdón general a los que habían destruido la catedral, cfr. Cortón de las Heras 1997: 60.

${ }^{84}$ Probablemente el ejemplo más contundente en este punto sea la llamada Guerra de los Campesinos Alemanes de la década de 1520. Sobre este punto pueden consultarse los clásicos trabajos de Peter Blickle, por ejemplo: Blickle 1981. 
Danvila y Collado, Manuel. 1897-1900. Historia crítica y documentada de las Comunidades de Castilla. Memorial Histórico Español, t. XXV-XL. Madrid, 6 vols.

Guevara, Antonio de. 2004. Obras Completas III. Epístolas Familiares, edición de Emilio Blanco. Madrid: Fundación José Antonio Castro.

Lecea y García, Carlos de (ed.). 1899. «Memorial histórico de Segovia, escrito por don Juan de Pantigoso en 1523». Boletín de la Real Academia de la Historia 14: 214-261.

Maldonado, Juan. 1991. Motu Hispaniae, edición y traducción de María Ángeles Durán Ramas. Madrid: Centro de Estudios Constitucionales.

Nieto Soria, José Manuel (ed.). 2015. De Enrique IV al emperador Carlos. Crónica castellana de 1454 a 1536. Madrid: Silex.

Santa Cruz, Alonso de. 1920. Crónica del Emperador Carlos V, edición de Antonio Blázquez y Ricardo Beltrán y Róspide. Madrid: Real Academia de la Historia, 3 vols.

\section{BiBLIOGRAFÍA}

Albert, Jean-Pierre. 1990. Odeurs de sainteté. La mythologie chrétienne des aromates. París: Ecole des Hautes Études en Sciences Sociales.

Álvarez de Frutos, Pedro. 1984. "Segovia y la guerra de las Comunidades: análisis social». Hispania XLIV, 158: 469-494.

Álvarez de Frutos, Pedro. 1987. La Revolución Comunera en tierras de Segovia. Madrid: Confederación Española de Cajas de Ahorros.

Ames, Christine Caldwell. 2012. «Medieval Religious, Religions, Religion». History Compass 10 (4): 334-352. https://doi. org/10.1111/j.1478-0542.2012.00836.x

Ames, Christine Caldwell. 2014. «Authentic, true and right: Inquisition and the study of Medieval Popular Religion». En Christianity and Culture in the Middle Ages: Essays to honor John Van Engen, editado por David C. Mengel y Lisa Wolverton, 87-119. Notre Dame: University of Notre Dame Press.

Asenjo González, María. 1986. Segovia. La ciudad y su tierra a fines del Medievo. Segovia: Diputación Provincial de Segovia.

Baschet, Jérôme. 2009. La civilización feudal. Europa del año mil a la colonización de América. México: FCE.

Benigno, Francesco. 2013. Las palabras del tiempo. Un ideario para pensar históricamente. Madrid: Cátedra.

Blickle, Peter. 1981. The Revolution of 1525: The German Peasants' War from a new perspective. Baltimore: The John Hopkins University Press.

Brown, Peter. 1981. The cult of the Saints: Its rise and function in Latin Christianity. Chicago: Chicago University Press.

Carroll, Stuart. 2006. Blood and violence in Early Modern France. Oxford: Oxford University Press.

Certeau, Michel de. 1981. "Une pratique sociale de la différence: croire», en Faire croire. Modalités de la diffusion et de la réception des messages religieux du XIle au XVe siècle, 363-383. Roma : École Française de Rome.

Christin, Olivier. 1991. Une révolution symbolique. L'iconoclasme huguenot et la reconstruction catholique. París: Les Éditions de Minuit.

Cillanueva de Santos, Miguel Ángel. 2009. La construcción de la Catedral de Segovia a través de sus cuentas. Estudio patrimonial, financiero y contable de la edificación de la "Dama de las Catedrales». Segovia: Caja de Segovia.

Congar, Yves. 1976. Eclesiología. De San Agustín hasta nuestros días. Madrid: BAC.

Contreras Jiménez, María Eugenia. 1989. "Noticias sobre la antigua catedral de Segovia. El hallazgo de San Frutos». Anuario de Estudios medievales 19: 507-520.

Cortón de las Heras, María Teresa. 1997. La construcción de la Catedral de Segovia (1525-1607). Segovia: Caja de Ahorros y Monte de Piedad de Segovia.

De La Peña Barroso, Efrén. 2015. «La Comunidad de Segovia y la familia Coronel». En Carlos V. Conversos y Comuneros. Liber Amicorum Joseph Pérez, editado por István Szaszdi León-Borja y María Jesús Galende Ruiz, 51-69. Valladolid: Centro de Estudios Camino Santiago Sahagún.
Delgado Ruiz, Manuel. 2001. Luces iconoclastas. Anticlericalismo, espacio y ritual en la España contemporánea. Barcelona: Ariel.

Denifle, Heinrich. 1897-1899. La désolation des églises, monastères et hôpitaux en France pendant la guerre de Cent Ans. París: Alphonse Picard et files, $3 \mathrm{t}$.

Derrida, Jacques. 1995. Espectros de Marx. El Estado de la deuda, el trabajo del duelo y la nueva Internacional. Madrid: Trotta

Dykema, Peter A. y Heiko A. Oberman. 1994. Anticlericalism in Late Medieval and Early Modern Europe. Leiden: Brill.

Eire, Carlos M. N. 1989. War against the Idols: The Reformation of worship from Erasmus to Calvin. Cambridge: Cambridge University Press.

Fernández Martín, Luis. 1979. El movimiento comunero en los pueblos de Tierra de Campos. León: Caja de Ahorros y Monte de PiedadArchivo Histórico Diocesano.

Fernández Martín, Luis. 1981. Juan Bravo. Segovia: Publicaciones de la Caja de Ahorros y Monte de Piedad de Segovia.

García de Cortázar, José Ángel (ed.). 1999. Del Cantábrico al Duero. Trece estudios sobre organización social del espacio en los siglos VIII a XIII. Santander: Universidad de Cantabria.

García de Cortázar, José Ángel. 2004. Sociedad y organización del espacio en la España Medieval. Granada: Editorial Universidad de Granada.

García de Cortázar, José Ángel. 2012. Historia religiosa del Occidente medieval. Madrid: Akal.

García de Cortázar, José Ángel y Ramón Teja Casuso (coords.). 2016. Los monasterios medievales en sus emplazamientos. Lugares de memoria de lo sagrado. Aguilar de Campoo: Fundación Santa María La Real.

García y García, Heliodoro. 1983. El pensamiento comunero y erasmista de Juan Maldonado. Madrid: s. e.

Geary, Patrick J. 1990. Furta Sacra: Thefts of relics in the Central Middle Ages. Princeton: Princeton University Press.

Ginzburg, Carlo. 2004. «Saqueos Rituales. Premisas para una investigación en curso». En Tentativas, 89-108. Rosario: Prohistoria.

Guerreau, Alain. 2002. El futuro de un pasado. La Edad Media en el siglo XXI. Barcelona: Crítica.

Guiance, Ariel. 2009. «En olor de santidad: la caracterización y alcance de los aromas en la hagiografía hispana medieval». Edad Media 10: 131-161.

Gutiérrez Nieto, Juan Ignacio. 1973. Las comunidades como movimiento antiseñorial (la formación del bando realista en la guerra civil castellana de 1520-1521). Barcelona: Planeta.

Haliczer, Stephen. 1976. "Political Opposition and Collective Violence in Segovia 1475-1520». Journal of Modern History 48: 1-35. https://doi.org/10.1086/241530

logna-Prat, Dominique. 2012 La Maison Dieu. Une histoire monumentale de l'Église au Moyen Âge. París: Seuil.

logna-Prat, Dominique. 2016a. Cité de Dieu, Cité des Hommes. L'Église et l'árchitecture de la société. París: PUF.

logna-Prat, Dominique. 2016b. La invención social de la Iglesia en la Edad Media. Buenos Aires: Miño y Dávila.

Kieckhefer, Richard. 2004. Theology in Stone: Church Architecture from Byzantium to Berkeley. Nueva York: Oxford University Press.

Kleinberg, Aviad. 2005. Histoire de saints. Leur rôle dans la formation de l'Occident. París: Gallimard.

Kotecki, Radosław y Jacek Maciejewski (eds.). 2014. Ecclesia et Violentia: Violence against the Church and violence within the Church in the Middle Ages. Cambridge: Cambridge Scholars Publishing.

Kracauer, Siegfried. 2010. Historia. Las últimas cosas antes de las últimas. Buenos Aires: Las cuarenta.

Küng, Hans. 1968. La Iglesia. Barcelona: Herder.

Langmuir, Gavin I. 1990. History, Religion and Antisemitism. Berkeley: University of California Press.

Lauwers, Michel. 2005. Naissance du cimetière. Lieux sacrés et terre des morts dans l'Occident médiéval. París: Aubier.

Lecea y García, Carlos de. 1906. Relación histórica de los principales comuneros segovianos. Segovia: Imprenta del Diario de Avisos. 
López Díez, María. 2006. Los Trastámara en Segovia. Juan Guas, Maestro de Obras Reales. Segovia: Caja Segovia.

MacKay, Angus y Geraldine McKendrick. 1988. «La semiología y los ritos de la violencia. Sociedad y poder en la Corona de Castilla». En la España Medieval 11: 153-165.

Maravall, José Antonio. 1979. Las comunidades de Castilla. Una primera revolución moderna. Madrid: Alianza

Marchal, Guy P. 1995. «Jalons pour une histoire de l'iconoclasme au Moyen Âge». Annales. Histoire, Sciences Sociales 50 (5): 11351156. https://doi.org/10.3406/ahess.1995.279420

Martínez Gil, Fernando. 2002. «Furia popular. La participación de las multitudes urbanas en las Comunidades de Castilla». En En torno a las Comunidades de Castilla. Actas del Congreso Internacional Poder, conflicto y revuelta en la España de Carlos I, coordinado por Fernando Martínez Gil, 309-364. Cuenca: Ediciones Castilla-La Mancha.

Modigliani, Anna y Andreas Rehberg. 2008. "“Saccheggi rituali" nell'ambito curiale-romano: una chimera degli antropologi?». Roma nel Rinascimento: 25-36.

Muchembled, Robert. 2010. Una historia de la violencia. Del final de la Edad Media a la actualidad. Barcelona: Paidós.

Oliva Herrer, Hipólito Rafael. 2018. «Juntar al pueblo: sobre las dimensiones espaciales de la movilización popular en las ciudades castellanas (siglos XV al XVI)». Trabajos y comunicaciones 48, e068. https://doi.org/10.24215/23468971e068

Pastoureau, Michel. 2006. Una historia simbólica de la Edad Media Occidental. Buenos Aires: Katz

Pérez, Joseph. 1999. La revolución de las Comunidades de Castilla (1520-1521). Madrid: Siglo XXI.

Pié-Ninot, Salvador. 2006. Eclesiología. La sacramentalidad de la comunidad cristiana. Salamanca: Sígueme.

Rizzuto, Claudio César. 2014. «Pensar con demonios entre los comuneros de Castilla. El diablo y la revuelta de las Comunidades (15201521)». Sociedades Precapitalistas 4: 1-28.

Rizzuto, Claudio César. 2015. «El problema de las relaciones entre herejía y rebelión en el contexto de la Revuelta Comunera (Castilla, 1520-1521)». Tiempos Modernos 8 (30): 1-30.
Rollo-Koster, Joëlle. 2014. «Episcopal and papal vacancies: A long history of violence». En Ecclesia et Violentia: Violence against the Church and violence within the Church in the Middle Ages, editado por Radosław Kotecki y Jacek Maciejewski, 54-70. Cambridge: Cambridge Scholars Publishing.

Sánchez León, Pablo. 1998. Absolutismo y Comunidad. Los orígenes sociales de la guerra de los comuneros de Castilla. Madrid: Siglo XXI.

Sigal, Pierre-André. 1985. L'homme et le miracle dans la France médiévale, Xle-XIle siècle. París: Cerf.

Soto Cano, María. 2005. «El traslado de la catedral de Segovia. Propuestas y actuaciones entre la segunda mitad del siglo XV y 1523». En Catedral y ciudad medieval en la Península Ibérica, editado por Eduardo Carrero Santamaría y Daniel Rico Camps, 215242. Murcia: Nausicaa.

Van Engen, John. 1986. "The Christian Middle Ages as an Historiographical Problem». The American History Review 91 (3): 519-552. https://doi.org/10.2307/1869130

Van Engen, John. 2008. «Multiple Options: The world of FifteenthCentury Church». Church History 77 (2): 257-284. https://doi. org/10.1017/s0009640708000541

Vaquero Serrano, María del Carmen, Tomás López Muñoz, María Luisa Picón García y María Ortiz Díez (eds.). 2001. El proceso contra Juan Gaitán. Toledo: Imprenta Serrano.

Vasallo Toranzo, Luis. 2017. «Guerra y destrucción del patrimonio: las Comunidades de Castilla contra Antonio Fonseca». En Días de otoño, tardes de archivo. Buenos y malos pleitos en la Real Chancilleria de Valladolid, coordinado por David Carvajal de la Vega y Cristina Emperador Ortega, 49-57. Madrid: Ministerio de Educación y Deporte.

Vauchez, André. 2014. La sainteté en Occident aux derniers siècles du Moyen Âge (1198-1431). Recherches sur les mentalités religieuses médiévales. Rome: École Française de Rome.

Ward, Benedicta. 1987. Miracles and the Medieval Mind: Theory, Record and Event, 1000-1215. Aldershot: Wildwood House.

Zumthor, Paul. 1994. La medida del mundo. Representación del espacio en la Edad Media. Madrid: Cátedra. 